\title{
Effects of Bystander's Emotional Empathy and Social Problem-Solving Skills on Defending Behaviors Against Bullying in Elementary School: Mediated Through Peer Acceptance
}

\author{
He Sook Nancy Kim¹, Kyung Ja Park ${ }^{2}$ \\ Lecturer, Department of Child \& Family Studies, Yonsei University, Seoul, Korea ${ }^{1}$ \\ Professor, Department of Child \& Family Studies, Human Life and Innovative Design, Yonsei University, Seoul, Korea ${ }^{2}$ \\ 초등학생 방관자의 공감, 사회적 문제해결 능력이 또래 괴롭힘 피해자를 위한 \\ 방어행동에 미치는 영향: 또래 수용의 매개 효과 \\ 김희숙 ${ }^{1}$ 박경자 ${ }^{2}$ \\ 연세대학교 아동가족학과 객원교수 ${ }^{1}$, 연세대학교 아동가족학과 인간생애와 혁신적 디자인 교수 ${ }^{2}$
}

Objectives: Many children are exposed to their peers being bullied, which negatively impacts individuals and the society as a whole. We investigated the effects of elementary school children's emotional empathy and social problem-solving skills on their defending behaviors. We evaluated the direct and indirect effects of these personal characteristics, mediated through their perceived peer acceptance among classmates. Gender differences were also tested.

Methods: The study participants were 386 fourth- and fifth-graders ( $M=10.4 \mathrm{yrs}$.) from six elementary schools in the metropolitan Seoul area of South Korea. Children's perceived social acceptance, emotional empathy, and problem-solving skills were measured using self-reported questionnaires. Defending behavior was measured using peer nomination. To analyze the data, descriptive statistics and structural equation modeling were conducted using SPSS 21.0 and MPLUS 6.12.

Results: Bystanders' emotional empathy and social problem-solving skills had significant effects on defending behaviors. Social problem-solving skills directly affected defending behaviors of boys and girls. Girls' peer acceptance mediated both emotional empathy and social problem-solving skills for defending behaviors, while no mediation effect was found in boys.

Conclusion: For children, feeling accepted by classmates is important for defending bullied peers. For girls, peer acceptance magnifies their socio-emotional and socio-cognitive skills, empowering them to defend the bullied peers. However, for boys, having competent socio-cognitive skills alone is sufficient. Based on this study's findings, it is recommended that interventions are needed to enhance bystanders' emotional empathy and social problem-solving skills, and thereby, empowering them to be competent defenders against school bullying.

Keywords: bullying, defending behaviors, bystander's emotional empathy, social problem-solving skills, perceived peer acceptance

Corresponding Author: Kyung Ja Park, Department of Child \& Family Studies, Human Life and Innovative Design, Yonsei University, Professor, 50 Yonsei-ro Seodaemun-gu, Seoul, Korea

E-mail: kjpark@yonsei.ac.kr
(C) The Korean Association of Child Studies

This is an Open Access article distributed under the terms of the Creative Commons Attribution Non-Commercial License (http:// creativecommons.org/licenses/by-nc/4.0) which permits unrestricted noncommercial use, distribution, and reproduction in any medium, provided the original work is properly cited. 


\section{Introduction}

School bullying has become a social problem which has longlasting, and often lifelong effects on the lives of many children and adolescents. School bullying is defined as repeated deliberate physical and verbal aggression inflicted by perpetrators who have more power over the victims with less power in class (Olweus, 2003). In school bullying situations, the entire class encounters the dire consequences of bullying since the bullies, victims, and bystanders suffer the detrimental effects, some more than others. Victims have reported suffering from depression, loneliness, anxiety, and lower self-esteem (Greener, 2016), sometimes resorting to attempting suicide (Kim \& Jung, 2015). In South Korea, bullying starts as early as in the fourth grades of elementary school. Its impact is devastating for the individual and society. One out of every four suicide attempts is primarily due to interpersonal conflicts experienced in school (Ministry of Education, 2019). Bullies are likely to become delinquents who abuse illicit drug and have drinking problems, and drop out of school during adolescence (Gini \& Pozzoli, 2013). The impact on bystanders who indirectly experience bullying is also significant. Many of whom have complained about social and psychological pressure and anxiety due to exposure to bullying (Lee, 2013). That is, the entire class experiences the dire consequences of bullying.

School bullying is a group phenomenon, and researchers have investigated the relationships between bystanders and victims (Juvonen \& Galván, 2008). Bystanders refer to individuals other than the bullies and victims who are involved in bullying episodes. Bystanders may include bully-assistants, bully-reinforcers, defenders, and outsiders/spectators. Over 70 percent of the time, bystanders watch when bullying occurs. They take on different roles related to starting, maintaining, or ending the bullying process (Polanin, Espelage, \& Pigott, 2012).

Among bystanders' different roles, their defending behaviors are crucial in ending the bullying process (Salmivalli, Voeten, \& Poskiparta, 2011). Defending behaviors are prosocial actions rooted in the resolute personal obligation for the well-being of the bullied victim, which overrides self-concerns despite the risks of retaliation and burdens of protective care (Juvonen \& Galván, 2008). They range from indirect assistance such as comforting the victim to direct action such as getting help from teachers and others to stop the bullying (Pozzoli \& Gini, 2010). When elementary school children stood up against bullies, 57\%-59 percent of the time, their interventional efforts stopped the bullying within 10 seconds (Fekkes, Pijpers, \& Verloove-Vanhorick, 2005). Despite its effectiveness, few studies have focused on the behaviors of bystander defenders during childhood. In this study, the authors investigated the defending behaviors of fourth and fifth graders in South Korea, using data collected from self-reports and nominations by their classmates based on how each student perceives their classmates.

Defending children and adolescents is often helpful, sociable, and empathic. Comparative studies on nominated bullies, victims, and defenders, found that the defenders had a greater understanding of peers' emotional and cognitive states (Cha \& Park, 2011; Oh \& Park, 2020), and they were more empathic than the bullies (Warden \& Mackinnon, 2003). Empathy is "the ability to understand and share another's emotional state or context"(Cohen \& Strayer, 1996). Evidence supports the notion that empathy is one of the most prominent traits of defenders.

However, other studies failed to find a significant association between defenders and empathy. A comparative study reported that the defender and outsider groups perceived and shared the victim's suffering at least to a moderate degree (Gini, Albiero, Benelli, \& Altoè, 2008). However, the defender group helped the victim while the outsiders remained silent or indifferent, dismissing the suffering of the bullied individual. Furthermore, even if there was an association between empathy and prosocial behaviors, it was insignificant (Wentzel, Filisetti, \& Looney, 2007).

There are several possible explanations for bystanders who often empathize with the victims but do not take on a defender's role. First, empathy consists of two distinctive emotional and cognitive dimensions (Gini, Albiero, Benelli, \& Altoè, 2007). Emotionally empathetic children were likely to be defenders in bullying situations, however, cognitively empathetic ones were likely to be the bullies (Caravita, Di Blasio, \& Salmivalli, 2009). These findings suggest that those who are cognitively empathetic may antagonize classmates, whereas those who are emotionally empathetic may comfort the victims. Hence, in this study, between the two types of empathy, emotional empathy was selected as a better predictor of defending behaviors in bullying situations.

Second, the gender of the bystanders might explain why some bystanders defended the victims whereas others did not (Espelage, 
Mebane, \& Adams, 2004; Parris et al., 2020). Researchers have reported that girls, compared to boys, expressed higher levels of personal distress in response to empathic stimuli (Rose \& Rudolph, 2006). Additionally, for boys, emotional empathy, not cognitive empathy, was associated with defending behaviors (Caravita et al., 2009). Moreover, when the effects of gender and peer expectations were controlled, neither empathy nor perspective-taking in older children were correlated with prosocial behaviors (Wentzel et al., 2007). This warrants the need to study how gender differences in children, with regard to emotional empathy, are related to the defending behavior of bystanders.

Third, other personal characteristics may have an influence on whether the bystander helps the victim. Children who were considered highly empathetic and socio-cognitively well developed had the reputation of being defenders in their class (Galinsky, Maddux, Gilin, \& White, 2008). They were more likely to have socially appropriate behaviors and cope constructively with a variety of challenges they encounter. That is, they had competent social problem-solving skills (Shure \& Spivack, 1972). Meansends thinking refers to people's ability to conceptualize various alternatives or a series of means that may be needed to resolve interpersonal conflicts that have emerged. Furthermore, it is a significant predictor of their prosocial behaviors, such as exhibiting concerns for others, being liked by peers, and being social (Pelligrini, 1985; Spivack \& Shure, 1982). The deficit in the means-ends thinking ability in school children was closely related to anxiety, dissatisfaction, withdrawal, or impulsivity (Richard \& Dodge, 1982), resulting in holding less favorable or withdrawn positions among their peers (Caravita, Gini, \& Pozzoli, 2012).

Social problem-solving skills, however, had inconsistent effects on prosocial behaviors by children's gender. In Shure's (1980) study with fourth-graders, boys with problem-solving skills were found to have more prosocial behavors, whereas girls with these skills were reported as being liked by their peers and more socially outgoing by both teachers and peers, and less inhibited or withdrawn by teachers. That is, problem-solving skills in boys were predictors of prosocial behavior. However, these skills in girls were predictors of a socially positive reputation in their class. This implies that the impact/influence of social problem-solving skills with regard to children's social likeability (i.e., peer acceptance) on generating defending behaviors requires further investigation.
Studies have provided some support for the critical role of children's peer relationships with regard to the influence of personal characteristics on defending behaviors in bullying situations (Gini et al., 2007, 2008). Children with high peer acceptance demonstrated high emotional empathy, eliciting more defending behaviors (Cravita et al., 2009). Salmivalli, Lagerspetz, Björkqvist, Österman and Kaukiainen (1996) reported the indirect effect of children's empathy through their social status in class on their defending behaviors. They explained that empathic children were popular among classmates and were, therefore, not concerned about the retaliation they may face from the bully for their defending behaviors, since they may receive support from their classmates. Their evaluation of their relationships with their peers seemed to function as a protective mechanism which allows them to act upon their wish to help their victimized peer (Pöyhönen, Juvonen, \& Salmivalli, 2010). Furthermore, Caravita et al. (2012) postulated that this relational factor acts as a magnifying lens that strengthens children's characteristics to help them defend the victim from the bully.

Nonetheless, to date, there has not been sufficient research on how peer acceptance mediates the effects of children's problemsolving skills on defending behaviors among elementary students. Since the findings of previous studies are not sufficient to reach a conclusion, further research on this topic is needed.

This study attempted to obtain a more accurate understanding of how children's emotional empathy and social problem-solving skills facilitate their peer acceptance in class and, in turn, influence their defending behaviors. Further, we investigated whether there exist gender differences. By doing so, we aimed to provide rudimentary information about the way bystanders, during late childhood, are motivated to defend victims despite the threat of the bully's retaliation.

The following are the research questions:

\section{Research Question 1}

Do children's emotional empathy and social problem-solving skills directly affect defending behaviors and indirectly affect them through perceived peer acceptance?

\section{Research Question 2}

Are the gender differences in children's emotional empathy and 


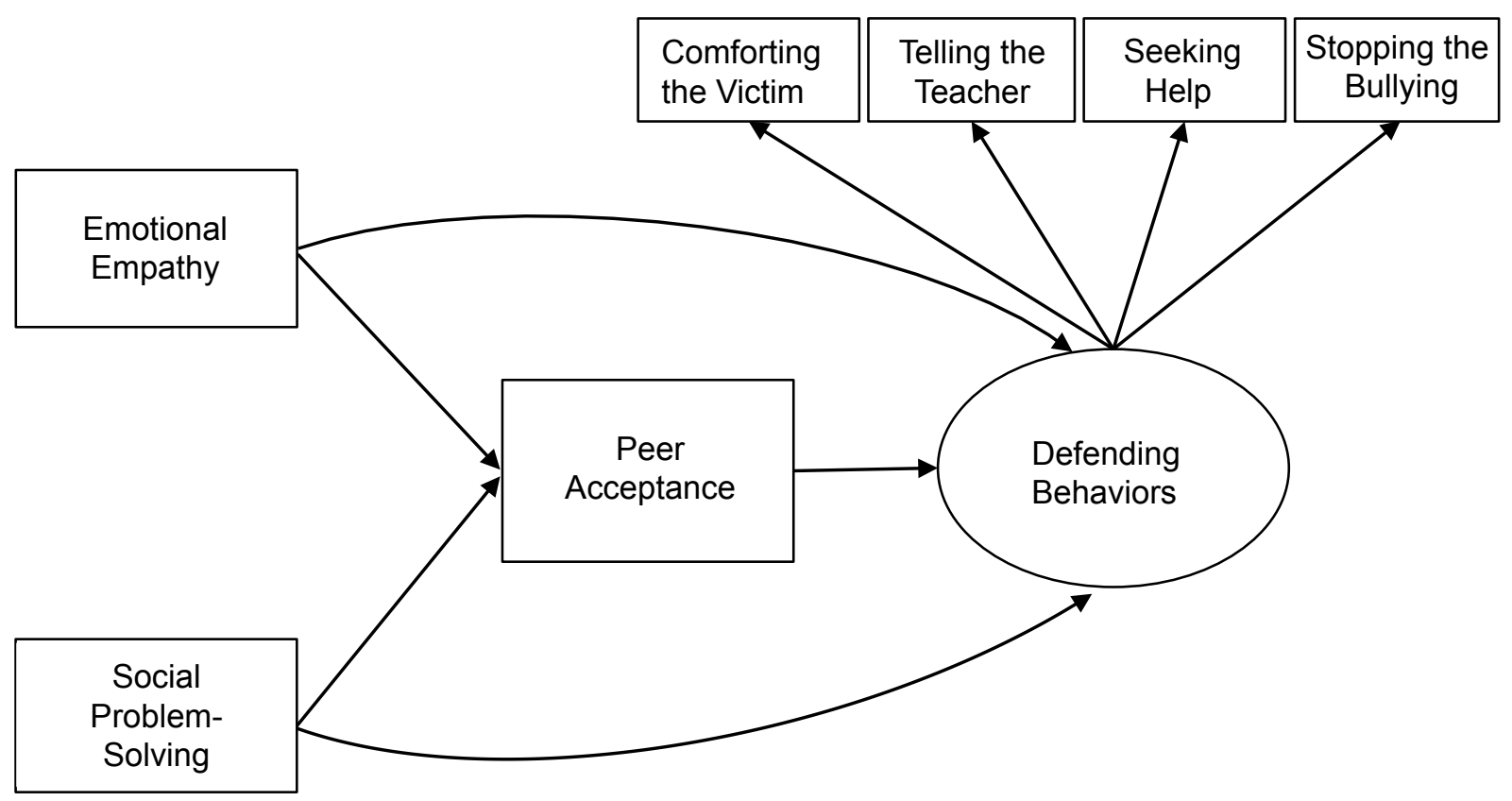

Figure 1. The conceptual model.

social problem-solving skills, directly or indirectly, generating the defending behaviors mediated through perceived peer acceptance?

To investigate the aforementioned research questions, the conceptual model shown in Figure 1 was developed.

\section{Methods}

\section{Participants}

The participants consisted of 386 children-196 fourth-graders (101 boys and 95 girls) from 11 classes and 190 fifth-graders (92 boys and 98 girls) from 13 classes in six elementary schools located in the greater metropolitan Seoul area of South Korea. The mean age of the children was 10.4 years (range: 9-12; $S D=.61$ ). Before the beginning the survey, of the 569 parents or legal guardians of the children who were initially recruited, 388 (67.19\%) returned signed consent forms, indicating their willingness to participate in the study. The final sample excluded two participants whose questionnaires were incomplete, resulting in 386 children.

\section{Instruments}

\section{Defending Behaviors}

The defender scale from the Participant Role Questionnaire (Salmivalli \& Voeten, 2004) was used to assess children's defending behaviors. The defender scale consisted of four items: comforting the victim, encouraging the victim to tell the teacher about the bullying, seeking others' help to stop bullying, and telling the bully to stop bullying.

The children were given a nomination form with the names of their classmates, next to four columns pertaining to defending behaviors. To avoid self-nomination the participant's name was crossed out from the roster in their nomination form. If a defending behavior was expected, the children marked the names of their classmates, whose typical behaviors fit each defending behavior. Proportional scores were calculated by dividing the score each child received from their classmates by the number of respondents. The higher the peer-nomination scores, the greater the likelihood that the nominee defended a victimized peer in bullying situations. The Cronbach's $\alpha$ coefficient for the defender scale was .88 . 


\section{Emotional Empathy}

The Empathy Scales (Eisenberg et al., 1996) was used to assess the emotional empathetic tendency of the children. The measure contained four items pertaining to their empathy for the less fortunate and assessed their tendency to have concerns, feel the victim's agony, and empathize with the victim. The children rated each item on a 5 -point, Likert scale $(1=$ never, $2=$ seldom, $3=$ sometimes, $4=$ usually, $5=$ always). Higher scores are indicative of higher levels of empathy. Cronbach's $\alpha$ coefficient for this scale was .75 .

\section{Social Problem-Solving Skills}

The Means-Ends Problem-Solving (MEPS; Spivack, Shure, \& Platt, 1985) procedure was used to measure social problem-solving skills. The MEPS procedure consisted of three conflicting social episodes that children generally encounter in school (for example, "Receiving nasty remarks, moving to a new neighborhood, and wanting to be elected as the class president."). Each episode had a beginning and an ending story (for example, "Friends seem to be avoiding Sam/SusanSam/Susan... now they like him/her again.”). The children were asked to complete the story based on how they would usually solve the given interpersonal problem to meet the stated ending in each episode.

The contents of the children's stories were coded for three different aspects of means-ends thinking; means, time sequence, and anticipated obstacles. The coding for means included the frequencies of their appropriateness in episode's contexts (for example, "My birthday is coming up soon, and I made an invitation card to invite new friends to get to know them.") and the involvement of a third-person (for example, "I asked my sister for a piece of advice.") to resolve this issue. The coding for time sequence involved steps to resolve a problem (for example, "First, second, third, ..”), duration (for example, "I take several days to think it over."), and timing (for example, "I wait until someone shows interest."). Lastly, the coding for the anticipated obstacles included personal (for example, "Being very shy.") and situational barriers (for example, "It rained and we could not play outside.").

We established the criteria for coding means-end thinking based on the MEPS manual (Spivack et al., 1985), and empirical data were collected during the pilot study portion of the research to deterimine the feasibility of its usage in the fifth grade elementary students. Each time a child wrote an item depicting any of the subdomains (means, time sequences, and obstacles), they received a point. We calculated the total means of the problem-solving skill (MEPS) scores. A high total score indicated the child's ability to conceptualize the means, consider time factors, and predict possible barriers while solving social problems. The inter-rater reliability, based on the coded data of 88 randomly-selected participants ( $22.80 \%$ of the total sample), was .83 .

\section{Self-perceived Peer Acceptance}

The Relations with Peer subscale of the Self-Description Questionnaire (SDQ; Marsh, Relich, \& Smith, 1983) was used to assess peer acceptance among classmates. It comprised eight items, each rated on a 4-point Likert scale ( $1=$ never, 2 = seldom, $3=$ sometimes, $4=$ usually, $5=$ always). Children rated themselves on how well they were accepted or liked by their peers in class, demonstrating their confidence in sociability and popularity among their classmates. The final item was reverse-coded. Higher scores indicated higher self-confidence regarding their perceived acceptance among their classmates. The Cronbach's $\alpha$ coefficient was 90 .

\section{Research Procedures}

We included elementary schools, that were near the university, from the public elementary schools listed on the Seoul Metropolitan Office of Education's website. We randomly selected 20 schools and sent out official letters via e-mails or fax to check whether they were interested in participating in the study. When a school's principal or teachers expressed their interest in the study, we visited the school and provided a brief presentation regarding the study to them, prior to conducting the survey.

In one of the participating elementary schools, a pilot study was conducted on 12 girls and 15 boys in the fifth-grade to check for the age-appropriateness of questionnaire items and simulate the actual survey procedures. For both the MEPS procedures and other items on the questionnaires, children took over an hour since each required 30-40 minutes to completed. They had a 10-minute break 
in between. The final data set excluded the data that was collected during the pilot study.

For the main study, only children whose parents submitted the signed consent form participated in the survey during their homeroom class. Those without consent forms opted to study, go to the library, or be in a different room and participate in other activities.

Each of the three well-trained researchers visited the participating classes and collected the completed questionnaires. As compensation for their participation, children received a small token of snacks.

\section{Statistical Analyses}

The examination of tolerance statistics indicated a non-violation of multicollinearity. The tolerance score was higher than .10, and the variance inflation factor (VIF) did not exceed 2 for all variables for appropriateness.

For descriptive information, we examined the distributions, means, t-tests, and correlations of variable scores. We proposed a hypothetical model of bystanders' emotional empathy and social problem-solving skills that affect peer acceptance, resulting in defending behaviors for the victim peer. As for the model test, we conducted structural equation modeling (SEM) analysis, using Mplus 6.12 (Muthèn \& Muthèn, 2010). The maximum likelihood method of estimation was employed to minimize the effect of missing data $(<4 \%$ of the total participants).

Mediation effects were assessed using the bootstrap method with 2,000 bootstrap replicates. The $95 \%$ confidence interval (CI) was evaluated.

To assess the parameters of each gender group, we performed a multi-group analysis using SEM. A null hypothesis of equality of path coefficients was examined in the proposed model for both boys and girls. Subsequently, Wald's chi-square test was conducted to confirm parameter inequality across the groups (Muthèn \& Muthèn, 2010). We presented standardized estimates and standard errors for the pathways in the studied model.

\section{Results}

\section{Descriptive Analyses and t-test Results}

The means $(M)$ and standard deviation $(S D)$ for the four types of defending behaviors ranged from comforting the victim in class the most $(M=0.37, S D=0.20)$ to stopping bullying the least $(M=$ $0.25, S D=0.17$ ) for all the participants (Table 1). However, unlike boys who showed similar degrees of ratings among the four types of behaviors, girls rated comforting the victim $(M=0.43, S D=0.20)$ the most and stopping the bullying $(M=0.26, S D=0.17)$ the least.

Table 1

Means, Standard Deviations, and t-tests Scores by Gender for Study Variables

\begin{tabular}{|c|c|c|c|c|c|c|}
\hline \multirow[b]{2}{*}{ Variables } & \multirow[b]{2}{*}{ Boy } & \multirow[b]{2}{*}{ Girl } & \multicolumn{3}{|c|}{$M(S D)$} & \multirow[t]{2}{*}{$t$-test } \\
\hline & & & Boy & Girl & Total & \\
\hline Comforting the victim & $0 \sim .91$ & $0 \sim .88$ & $.30(.17)$ & $.43(.20)$ & $.37(.20)$ & $-6.86^{* * *}$ \\
\hline Seeking help & $0 \sim .70$ & $0 \sim .82$ & $.25(.15)$ & $.30(.17)$ & $.28(.16)$ & $-3.20^{* *}$ \\
\hline Stopping the bullying & $0 \sim .71$ & $0 \sim .89$ & $.24(.16)$ & $.26(.17)$ & $.25(.17)$ & -1.04 \\
\hline Means & $1-19$ & $2-19$ & $8.39(3.28)$ & $9.65(3.43)$ & $9.02(3.41)$ & $-3.71^{* * *}$ \\
\hline Time & $0-7$ & $0-7$ & $1.47(1.57)$ & $1.65(1.70)$ & $1.56(1.63)$ & -1.06 \\
\hline Obstacles & $0-7$ & $0-8$ & $1.60(1.58)$ & $2.38(1.86)$ & $1.99(1.77)$ & $-4.46^{* * *}$ \\
\hline Problem-solving total & $1-30$ & $2-29$ & $11.46(4.82)$ & $13.68(5.19)$ & $12.57(5.12)$ & $-4.36^{* * *}$ \\
\hline Peer acceptance & $1-4$ & $1-4$ & $3.01(.56)$ & $3.09(.57)$ & $3.04(.56)$ & $-2.06^{*}$ \\
\hline
\end{tabular}

Note. $N=386$. There were 193 children in each group (boys and girls). In $t$-test, the boys and girls were classified as 1 and 2 , respectively. ${ }^{*} p<.05 .{ }^{* *} p<.01 .{ }^{* * *} p<.001$. 
Table 2

Correlations Among Research Variables by Gender

\begin{tabular}{|c|c|c|c|c|c|c|c|c|c|c|c|c|}
\hline & 1 & 2 & 3 & 4 & 5 & 6 & 7 & 8 & 9 & 10 & 11 & 12 \\
\hline 1. Grade $(1=4$ th, $2=5$ th $)$ & - & $-.15^{*}$ & $-.15^{*}$ & $-.18^{*}$ & $-.26^{* *}$ & $-.17^{* *}$ & .12 & .05 & .10 & $.17^{*}$ & .05 & .00 \\
\hline 2. Comforting the victim & $-.18^{*}$ & - & $.72^{* * *}$ & $.65^{* * *}$ & $.67^{* * *}$ & $.84^{* * *}$ & $.29^{* * *}$ & $.22^{* *}$ & $.16^{*}$ & $.33^{* * *}$ & $.26^{* * *}$ & .03 \\
\hline 4. Seeking help & $-.16^{*}$ & $.68^{* * *}$ & $.56^{* * *}$ & - & $.75^{* * *}$ & $.81^{* * *}$ & $.15^{*}$ & $.25^{* *}$ & .07 & $.24^{* *}$ & $.29^{* * *}$ & .02 \\
\hline 5. Stopping the bullying & $-.23^{* *}$ & $.63^{* * *}$ & $.62^{* * *}$ & $.72^{* * *}$ & - & $.82^{* * *}$ & $.24^{* *}$ & $.23^{* *}$ & .14 & $.30^{* * *}$ & $.28^{* * *}$ & .08 \\
\hline 8. Time & $.16^{*}$ & .13 & .13 & $.31^{* * *}$ & $.25^{* * *}$ & $.25^{* * *}$ & $.38^{* * *}$ & - & $.18^{*}$ & $.66^{* * *}$ & .13 & .08 \\
\hline 9. Obstacles & .13 & .02 & .10 & $.15^{*}$ & .13 & .13 & .09 & $.34^{* * *}$ & - & $.57^{* * *}$ & .10 & .14 \\
\hline 10. Problem-solving total & $.28^{* * *}$ & .13 & .11 & $.30^{* * *}$ & $.23^{* *}$ & $.23^{* *}$ & $.78^{* * *}$ & $.69^{* * *}$ & $.57^{* * *}$ & - & $.18^{*}$ & $.15^{*}$ \\
\hline 11. Peer acceptance & -.04 & .12 & .11 & $.21^{* *}$ & $.18^{*}$ & $.18^{*}$ & .12 & .00 & .12 & $.15^{*}$ & - & $.18^{*}$ \\
\hline
\end{tabular}

Note. Correlation coefficients below the diagonal line of dashes are those of boys and above it are those of girls. ${ }^{*} p<.05 .{ }^{* *} p<.01 .{ }^{* * *} p<.001$.

Children's self-rated emotional empathy had a mean score of $4.15(S D=0.99)$ with no significant gender differences (Table 1$)$. Their tendency for empathy indicated that children generally had a relatively high emotional empathy score.

In the MEPS task, the children enumerated the most number of means $(M=9.02, S D=3.41)$, followed by obstacles $(M=1.99$, $S D=1.77)$, and the least number of time expressions $(M=1.56$, $S D=1.63)$ as solutions to given episodes with conflicts of interest. They also created reality-based methods, obstacles, and time elements to resolve some of the challenges they are likely encounter in real life.

The mean score of peer acceptance was $3.04(S D=0.56$, range 1-4), which demonstrated the self-perception of being sociable and popular or at least wished to be considered as such in their class (Table 1). The results of t-tests indicated some significant gender differences in the total scores of all variables, except for time and emotional empathy, suggesting the possibility of two distinctive models for pathways by gender.

Correlation coefficients among demographic, independent, dependent, and mediator variables, by gender, are provided in Table 2 . The grade level was significantly correlated with the total scores of defending behaviors in boys $(r=-.21, p<.001)$ and girls $(r=-.17, p<.001)$. It was also significantly correlated with the social problem-solving skills of boys $(r=.28, p<.001)$ and girls $(r=.17, p<.05)$. The results of the t-test between the fourth- and the fifth-grade groups showed significant differences in defending behaviors $(t=3.52, p<.001)$ and social problem-solving skills $(t=$ $-4.51, p<.001)$. These two variables are closely related to maturity. As children's grade level increased in elementary school, their social and cognitive competencies were likely to improve due to maturation (Spivack \& Shure, 1982). Since this study did not aim to Investigate the effect of maturity on defending behaviors, we controlled for grade level in the model.

Emotional empathy was significantly associated with social problem-solving skills in both boys $(r=.18, p<.05)$ and girls $(r=$ $.15, p<.05)$. while it was only associated with peer acceptance $(r=$ $.18, p<.05)$ in girls.

Social problem-solving skills were significantly associated with defending behaviors for both boys $(r=.23, p<.001)$ and girls $(r=.28, p<.001)$. However, it was only correlated with peer acceptance in girls $(r=.28, p<.001)$. Peer acceptance was significantly correlated with defending behaviors for both boys $(r=$ $.18, p<.05)$ and girls $(r=.28, p<.001)$.

In short, both boys and girls who reported themselves to be highly empathetic toward the emotional well-being of others also had social problem-solving skills to solve interpersonal problems. However, only social problem-solving skills were related to their defending behaviors. Only for girls emotional empathy and social problem-solving skills were related to their peer acceptance. Overall, perceived peer acceptance was significantly correlated with defending behaviors. 
Table 3

Model-fit Indices of SEM and Multi-Group Analyses

\begin{tabular}{|c|c|c|c|c|c|c|c|}
\hline Models & $N$ & $\chi^{2}(\mathrm{df})$ & $p$ & $\begin{array}{c}\text { RMSEA } \\
(90 \% \mathrm{CI})\end{array}$ & SRMR & CFI & TLI \\
\hline Hypothesized full model & 386 & $49.73(12)$ & .00 & $\begin{array}{c}.10 \\
(.07 \sim .12)\end{array}$ & .03 & .96 & .92 \\
\hline Constraint model & 386 & $19.82(10)$ & .03 & $\begin{array}{c}.05 \\
(.02 \sim .08)\end{array}$ & .02 & .99 & .98 \\
\hline Multi-group model & 386 & $37.20(20)$ & .02 & $\begin{array}{c}.06 \\
(.23 \sim .09)\end{array}$ & .04 & .98 & .97 \\
\hline Wald test & 386 & $32.11(20)$ & .04 & $\begin{array}{c}.06 \\
(.01 \sim .09) \\
\end{array}$ & .05 & .99 & .97 \\
\hline
\end{tabular}

${ }^{*} p<.05 .{ }^{* *} p<.01 .{ }^{* * *} p<.001$.

\section{SEM Analyses}

In the full hypothesized model shown in Figure 2, the dependent variable, defending behavior, was created as a latent variable by compiling the four indicators of defending behaviors (comforting the victim, telling the teacher, seeking help, and stopping the bullying). Regarding the independent variables, the mean scores of emotional empathy and social problem solving with the three indicators (means, time, and obstacles) were calculated. For the mediator variable, the mean scores for perceived peer acceptance were used.

First, we conducted a SEM analysis of the full hypothesized model without any constraints to test its fit to the total sample. According to the fit indices of the SEM in Table 3, those of the full hypothesized model were not significant (insignificant $\chi^{2}$ value and RMSEA > .08). Second, the grade was controlled, and the covariance between emotional empathy and social problemsolving skills was constrained in the model. All the fit indices of the constraint model satisfied the evaluative criteria indices and indicated their significant fit to the data (Table 3).

The results indicated that both emotional empathy $(\beta=0.12$, $p<.05)$ and social problem-solving skills $(\beta=0.16, p<.01)$ significantly predicted peer acceptance $(\beta=0.19, p<.001)$ and, subsequently, defending behaviors. Only social problem-solving skills $(\beta=0.28, p<.001)$ directly predicted defending behaviors.

The mediation effects were tested using the bootstrap method. The results indicated that children's peer acceptance mediated the relationship between emotional empathy $(\beta=0.02, p<.05)$ and social problem-solving skills $(\beta=0.03, p<.05)$, and their defending behaviors. The 95\% CIs were evaluated and none of them included zero. The results confirmed the statistical significance of the mediation effects. That is, the more children were emotionally empathetic and competent in solving interpersonal problems, the more they were accepted by their classmates, resulting in more defending behaviors.

Consistent with the significant gender difference confirmed by t-tests (Table 1), we conducted a multi-group SEM, and the acceptable fit indices indicated significant differences in path estimates of the SEM model between gender groups (Table 3). The values of $\chi^{2}$ for the boy and girl groups were 26.87 and 10.57, respectively.

According to Figure 2, for girls, both emotional empathy and social problem-solving skills influence their peer acceptance among their classmates, which consequently acceptance empowered them to assume defending behaviors. However, for boys, only social problem-solving skills had a direct effect on their defending behaviors. That is, for girls, their emotional empathy alone was not sufficient for them to defend the victim. In addition, their social problem-solving skills worked, directly and indirectly, to motivate them to defend the victim.

To assess the differences in path estimates of the SEM model between gender groups, Wald's chi-square test of parameter constraints was conducted and found significant, Wald $\chi^{2}(1)=4.31$, $p<.05$, after the corresponding path parameters were constrained to be equal across gender groups. The results indicated that not all paths were equal between the groups. In Table 4, the estimates of distinctive paths in the current SEM model between the groups are presented as the results of the Wald test. Only the paths from 


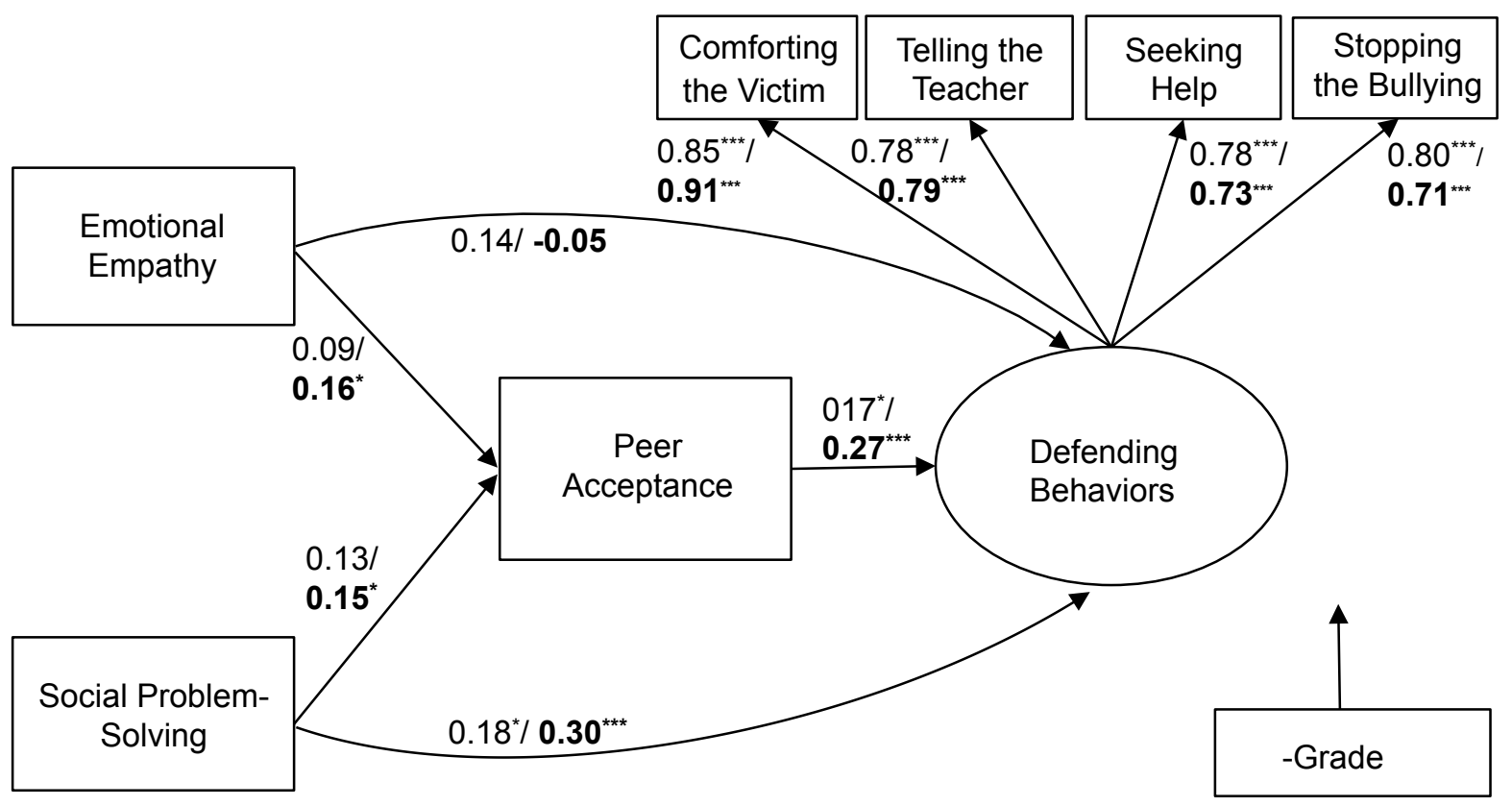

Figure 2. The constraint model with standardized path coefficients by gender.

Note. $N=386$. Estimates for paths are presented in the order of boys/girls.

${ }^{*} p<.05 .{ }^{* * *} p<.001$.

Table 4

Path Estimates of Current SEM by Gender: Results from Wald Test

\begin{tabular}{lllll}
\hline & \multicolumn{2}{c}{ Boy } & \multicolumn{2}{c}{ Girl } \\
\cline { 2 - 5 } \multicolumn{1}{c}{ Pathways } & $\beta$ & $S E$ & $\beta$ & $S E$ \\
\hline Emotional empathy $\rightarrow$ Defending behaviors & 0.03 & 0.06 & -0.01 & 0.08 \\
Social problem-solving $\rightarrow$ Defending behaviors & $0.24^{* *}$ & 0.07 & $0.38^{* * *}$ & 0.07 \\
Emotional empathy $\rightarrow$ Peer acceptance & 0.09 & 0.07 & $0.16^{*}$ & 0.07 \\
Social problem-solving $\rightarrow$ Peer acceptance & 0.13 & 0.07 & $0.15^{*}$ & 0.07 \\
Peer acceptance $\rightarrow$ Defending behaviors & $0.03^{* *}$ & 0.01 & $0.05^{* * *}$ & 0.01 \\
\hline
\end{tabular}

${ }^{*} p<.05 .{ }^{* *} p<.01 .{ }^{* * *} p<.001$.

emotional empathy and social problem-solving to peer acceptance showed differences across the gender groups.

\section{Discussion}

This study aimed to explore the relationships among emotional empathy, social problem-solving skills, perceived peer acceptance, and participation in defending behaviors using the SEM model. Our findings confirmed the vital role of children's peer acceptance, which mediates the effects of their emotional empathy and social problem-solving skills in promoting defending behaviors as bystanders in school bullying situations (Gini et al., 2008). It integrated self-perceived and other-perceived assessments of individual children's characteristics in the prediction of defending behaviors among fourth- and fifth-graders in elementary school.

The participants in this study indicated a high propensity to defend their bullied peer. Comforting the victim, seeking support from teachers and others, and telling the bully to stop were the defending behaviors, in the order from the most to least, respectively. It might be the degree to which the bystander- children contribute to others' well-being linked to their assertive responses, girls considering potential retaliation more than boys (Pöyhönen et al., 2010). 
The results showed that emotional empathy had significant positive and indirect effects on defending behaviors. Children with high emotional empathetic responsiveness were more likely to be accepted by peers and elicit more defensive behaviors in school bullying situations. In addition, the estimated indirect effect was greater than the estimated direct effect of emotional empathy in the SEM analysis. This suggests that children's high social position in class/acceptance or popularity could provide a platform for them to act on their empathetic feelings toward the victim. Our results are also consistent with those reported in another study. Children's confidence derived from peer acceptance seems at work, magnifying their abilities (Caravita et al., 2009).

The social problem-solving skills of the participants had both significantly positive direct and indirect effects on their defending behaviors. Those who were capable of planning various solutionalternative options in a step-by-step manner at the right time while considering realistic obstacles also defended victims. These abilities account for the qualities of so-called socially competent, self-reliant leaders in groups (Kleon \& Rinehart, 1998). Children who readily used means-ends thinking for hypothetical social conflicts tended to have concerns about the problems faced by peers, empathized with them, and were popular among their peers (Asher \& Renshaw, 1981). Previous studies also reported that boys and girls employing a self-sufficient strategy to solve social problems intrinsically possess strong self-efficacy which predicts high levels of global self-esteem to defend the victimized peers (Causey \& Dubow, 1992; Pozzoli \& Gini, 2010). The skills themselves are important to appropriately stratify the defending behavior for the victim, which may also serve to fortify their acceptance among their peers or may even become popular.

Supportive and defending behaviors toward the victim differed by gender. Girls tended to intervene for victims more than boys did. Specifically, unlike boys who showed a similar degree of ratings among all the four types of behaviors, girls comforted victims the most and stopped bullies the least. This means that, compared to boys whose mean scores for defending behaviors did not have much discrepancy, irrespective of whether the behavior was direct or indirect, girls had significantly more indirect and relational forms of defending (Vaillancourt \& Hymel, 2006), but not so much with regard to directly confronting the bully. Parris et al.(2020) suggested that girls used more constructive and internalized approaches to solve problems and seek social support compared to boys. Such gender differences may be due to socially constructed gender norms embedded in the way girls and boys build their friendships. According to Ging and O'Higgins Norman (2016), the observed relationships among girls tend to be more intense and intimate than those among boys. Girls are usually tend to a limited number of friends. In contrast, boys are socialized to be autonomous and goal-oriented. Girls' socialization and positive sense of self are focused on relationships and empathic connectedness. Hence, threats to relationships are perceived as threats to their sense of self. This suggests that girls, compared to boys, are more interested in maintaining friendships and resolving conflicts.

In the multi-group analysis by gender, a significant gender difference was that boys with the competency to solve interpersonal conflicts were likely to defend the bullied peer directly, regardless of their perceived acceptance/popularity in class, while girls with the same ability defended the victim both directly and indirectly through their peer acceptance or popularity. For boys, competency in social problem-solving skills was sufficient and motivated them to defend victim. However, even though girls were sufficiently skillful in solving relational problems, they sometimes heeded to their popularity in class to defend the victim (Thornberg \& Jungert, 2013). It has been reported that girls, compared to boys, often feel a higher level of personal distress in response to overwhelming events such as bullying. Girls may feel reposeful in group actions (Thornberg \& Jungert, 2013). However, boys may perceive a bullying incident as a one-time threat they need to work on to resolve, making it easier to take on a defensive role in such situations (Ging \& O’Higgins Norman, 2016). These differences can be individualized to promote appropriate defending behaviors in students to end school bullying.

Based on the findings of this study, we advocate for a multilevel bullying prevention program for bystanders so that they are motivated to become defenders for the victims in elementary school. The program includes the following aims: (1) to improve empathetic responsiveness by practicing sharing emotions, thinking from others' perspectives that may lead to more concrete and effective defending behaviors during role-play; (2) to help children think of or mentally process creative and effective ways to solve problems and expand their repertoires of means-end thinking so 
that they are empowered to successfully confront the bully; (3) to recognize and learn that interpersonal conflicts can often be prolonged and that they need endurance to find the right moments and ways to act via their carefully planned solution in various steps; (4) to take on a cooperative approach to motivate a group to arrive at mutually acceptable solutions for the conflicts through meetings and school-based training for interpersonal communication and counseling, ultimately building accountability among classmates; (5) to enhance awareness among parents and teachers regarding the detrimental consequences that bullying has on all participants in school and to involve them in the preventive process of eradicating school bullying.

This study has several limitations: First, the sample was limited to those whose parents provided written informed consent. Therefore, may have been biased to involve those students whose parents were inclined to help their bullied peers, and this inclination might have passed onto the children. Second, four different defending behaviors were compiled as latent variables. Differentiating direct and indirect behaviors would succinctly clarify the effects of the three variables on the development of bystanders' defending behaviors. Third, the model developed in this study included only personal and social factors. Other contextual factors such as teachers' attitudes about bullying and the children's family environments need further investigation to broaden the understanding of the factors that elicit bystanders' defending behaviors.

The findings of this study support that, for children to become defender-bystanders, they need to be emotionally empathetic toward the victim's suffering and have the cognitive competency to come up with a solution while considering interpersonal relationships as the situation demands. It may not be safe for the bystanders to defend the victim in all bullying situations. Therefore, there should be protective measures in schools and the society so that bystanders can speak up for and defend victims. Even though it was only seen in girls, this study substantially supported the hypothesis that the acceptance children receive from classmates magnify personal characteristics, such as emotional empathy and social problem-solving skills, thereby, empowering their defending behaviors. As for boys, high social problemsolving skills are sufficient for them to help the victim. Hence, for outsider-bystanders to become defender-bystanders, it is necessary to consider a developmental program individualized for students to bring out and develop emotional empathy and social problemsolving skills as a group.

\section{Notes}

Data collection and preliminary analyses were parts of the author's doctoral dissertation in Child \& Family Studies at Yonsei University Graduate School in Korea. The findings of this study were partially presented as a poster at Society for Research on Adolescence (SRA) 2021 Virtual meeting.

\section{Conflict of Interest}

No potential conflict of interest relevant to this article was reported.

\section{Ethics Statement}

All procedures of this research were reviewed by IRB (1040917201510-SB- 228-03).

\section{References}

\section{In English}

Asher, S. R., \& Renshaw, P. D. (1981). Children without friends: Social knowledge and social skills training. In S. R. Asher \& J. M. Gottman (Eds.), The development of children's friendships (pp. 273-296). New York: Cambridge University Press.

Caravita, S. C. S., Di Blasio, P., \& Salmivalli, C. (2009). Unique and interactive effects of empathy and social status on involvement in bullying. Social Development, 18(1), 140163. doi:10.1111/j.1467-9507.2008.00465.x

Caravita, S. C. S., Gini, G., \& Pozzoli, T. (2012). Main and moderated effects of moral cognition and status on bullying and defending. Aggressive Behavior, 38(6), 456-468. doi:10.1002/ab.21447

Causey, D. L., \& Dubow, E. F. (1992). Development of a selfreport coping measure for elementary school children. 
Journal of Clinical Child Psychology, 21(1), 47-59. doi:10.1207/s15374424jccp2101_8

Cohen, D., \& Strayer, J. (1996). Empathy in conduct-disordered and comparison youth. Retrieved from ERIC database. (EJ543359)

Eisenberg, N., Fabes, R. A., Karbon, M., Murphy, B. C., Wosinski, M., Polazzi, L., Garlo, G., \& Juhnke, C. (1996). The relations of children's dispositional prosocial behavior to emotionality, regulation, and social functioning. Child Development, 67(3), 974-992. doi:10.2307/1131874

Espelage, D. L., Mebane, S. E., \& Adams, R. S. (2004). Empathy, caring and bullying: Toward an understanding of complex associations. In D. L. Espelage \& S. M. Swearer (Eds.), Bullying in American schools: A social ecological perspective on prevention and intervention (pp. 37-61). Mahwah, NJ: Lawrence Erlbaum Associates.

Fekkes, M., Pijpers, F. I., \& Verloove-Vanhorick, S. P. (2005). Bullying: Who does what, when and where? Involvement of children, teachers and parents in bullying behavior. Health Education Research, 20(1), 81-91. doi:10.1093/her/cyg100

Galinsky, A. D., Maddux, W. W., Gilin, D., \& Whilte, J. B. (2008). Why it pays to get inside the head of your opponent. Psychological Science, 19(4), 378-384. doi:10.1111/j.14679280.2008.02096.x

Ging, D., \& O'Higgins Norman, J. (2016). Cyberbullying, conflict management or just messing? Teenage girls' understandings and experiences of gender, friendship, and conflict on facebook in an Irish second-level school. Feminist Media Studies, 16(5), 805-821. doi:10.1080/14680777.2015.1137959

Gini, G., Albiero, P., Benelli, B., \& Altoè, G. (2007). Does empathy predict adolescents' bullying and defending behavior? Aggressive Behavior, 33(5), 467-476. doi:10.1002/ab.20204

Gini, G., Albiero, P., Benelli, B., \& Altoè, G. (2008). Determinants of adolescents' active defending and passive bystanding behavior in bullying. Journal of Adolescence, 31, 93-105. doi:10.1016/j.adolescence.2007.05.002

Gini, G., \& Pozzoli, T. (2013). Bullied children and psychosomatic problems: A meta-analysis. Pediatrics, 132(4), 720-729. doi:10.1542/peds.2013-0614

Greener, M. (2016). Understanding the long-term effects of bullying. British Journal of School Nursing, 11(1), 36-39. doi:10.12968/bjsn.2016.11.1.36

Juvonen, J., \& Galván, A. (2008). Peer influence in voluntary social groups: Lessons from research on bullying. In M. J. Prinstein \& K. A. Dodge (Eds.), Understanding peer influence in children and adolescents (pp. 225-244). New York: Guilford Press.

Kleon, S., \& Rinehart, S. (1998). Leadership skill development of teen leaders. Retrieved from ERIC database. (EJ567021)

Marsh, H. W., Relich, J. D., \& Smith, I. D. (1983). Self- concept: The construct validity of interpretations based upon the Self-Description Questionnaire (SDQ). Journal of Personality and Social Psychology, 45(1), 173-187. doi:10.1037/0022-3514.45.1.173

Muthèn, L. K., \& Muthèn, B. O. (2010). Mplus User's Guide (6th ed.). Los Angeles, CA: Muthèn \& Muthèn.

Olweus, D. (2003). A profile of bullying at school. Retrieved from ERIC database. (EJ662681)

Parris, L., Jungert, T., Thornberg, R., Varjas, K., Meyers, J., Grunewald, S., \& Shriberg, D. (2020). Bullying bystander behaviors: The role of coping effectiveness and the moderating effect of gender. Scandinavian Journal of Psychology, 61(1), 38-46. doi:10.1111/sjop.12564

Pellegrini, D. S. (1985). Social cognition and competence in middle childhood. Child Development, 56(1), 253-264. doi:10.2307/1130192

Polanin, J. R., Espelage, D. L., \& Pigott, T. D. (2012). A metaanalysis of school-based bullying prevention programs' effects on bystander intervention behavior. School Psychology Review, 41(1), 47-65. doi:10.1080/02796015.2012.12087 375

Pöyhönen, V., Juvonen, J., \& Salmivalli, C. (2010). What does it take to stand up for the victim of bullying? The interplay between personal and social factors. Merrill-Palmer Quarterly, 56(2), 143-163. doi:10.1353/mpq.0.0046

Pozzoli, T., \& Gini, G. (2010). Active defending and passive bystanding behavior in bullying: The role of personal characteristics and perceived peer pressure. Journal of Abnormal Child Psychology, 38, 815-827. doi:10.1007/ s10802-010-9399-9

Richard, B. A., \& Dodge, K. A. (1982). Social maladjustment and problem solving in school-aged children. Journal of Consulting and Clinical Psychology, 50(2), 226-233. doi:10.1037/0022-006X.50.2.226

Rose, A. J., \& Rudolph, K. D. (2006). A review of sex differences in peer relationship processes: Potential trade-offs for the emotional and behavioral development of girls and boys. Psychological Bulletin, 132(1), 98-131. doi:10.1037/00332909.132.1.98

Salmivalli, C., Lagerspetz, K., Björkqvist, K., Österman, K., \& Kaukiainen, A. (1996). Bullying as a group process: Participant roles and their relations to social status within the group. Aggressive Behavior, 22(1), 1-15. doi:10.1002/ (SICI) 1098-2337(1996)22:1<1::AID-AB1>3.0.CO;2-T

Salmivalli, C., \& Voeten, M. (2004). Connections between attitudes, group norms, and behavior in bullying situations. International Journal of Behavioral Development, 28(3), 246258. doi:10.1080/01650250344000488

Salmivalli, C., Voeten, M., \& Poskiparta, E. (2011). Bystanders matter: Associations between reinforcing, defending, and 
the frequency of bullying behavior in classrooms. Journal of Clinical Child \& Adolescent Psychology, 40(5), 668-676. doi: 10.1080/15374416.2011.597090

Shure, M. (1980). Real-life problem solving for parents and children: An approach to social competence. In D. P. Rathjen \& J. P. Foreyt (Eds.), Social competence: Interventions for children and adults (pp. 54-69). Oxford, GB: Pergamom Press.

Shure, M. B., \& Spivack, G. (1972). Means-ends thinking, adjustment, and social class among elementary-schoolaged children. Journal of Consulting and Clinical Psychology, 38(3), 348-353. doi:10.1037/h0032919

Spivack, G., \& Shure, M. B. (1982). The cognition of social adjustment: Interpersonal cognitive problem solving thinking. In B. B. Lahey \& A. E. Kazdin (Eds.), Advances in Clinical Child Psychology (pp. 323-372). New York: Kluwer Academic/Plenum Publishers.

Spivack, G., Shure, M. B., \& Platt, J. J. (1985). Means-Ends Problem Solving (MEPS): Stimuli and Scoring Procedure (Unpublished manuscript, Hahnemann University). Philadelphia, PA: Prevention Intervention Research Center.

Thornberg, R., \& Jungert, T. (2013). Bystander behavior in bullying situations: Basic moral sensitivity, moral disengagement and defender self-efficacy. Journal of Adolescence, 36(3), 475-483. doi:10.1016/j.adolescence.2013.02.003

Vaillancourt, T., \& Hymel, S. (2006). Aggression and social status: The moderating roles of sex and peer valued characteristics. Aggressive Behavior, 32(4), 396-408. doi:10.1002/ab.20138

Warden, D., \& Mackinnon, S. (2003). Prosocial children, bullies and victims: An investigation of their sociometric status, empathy and social problem solving strategies. British Journal of Developmental Psychology, 21(3), 367-385. doi:10.1348/026151003322277757

Wentzel, K. R., Filisetti, L., \& Looney, L. (2007). Adolescent prosocial behavior: The role of self-processes and contextual cues. Child Development, 78(3), 895-910. doi:10.1111/ j.1467-8624.2007.01039.x

\section{In Korean}

Cha, Y., \& Park, K. J. (2011). School children's roles and social understanding in peer bullying. Journal of Life-span Studies, 1(1), 47-67.

Kim, K., \& Jung, J. (2015). Analysis of suicidal ideation pathways and marginal effects in school bullying victims. Health and Welfare Policy Forum, 220, 81-101.

Lee, S.-Y. (2013). School bullying: Need for bystander intervention and change of social context. The Korean Journal of School Psychology, 10(1), 59-82. doi:10.16983/kjsp.2013.10.1.59

Ministry of Education. (2019). 2019nyeon 1cha haggyopoglyeog siltaejosa gyeolgwa balpyo [2019년 1차 학교폭력 실태 조사 결과 발표]. Retrieved from https://if-blog.tistory. $\mathrm{com} / 9216$

Oh, S. C., \& Park, J. H. (2020). Influence of bullying victimization on defending behavior against bullying among upper elementary students and the multiple additive moderating effect of affective empathy and perceived social support. Korean Journal of Child Studies, 41(6), 81-93. doi:10.5723/ kjcs.2020.41.6.81

\section{ORCID}

He Sook Nancy Kim http://orcid.org/0000-0003-4122-4732

Kyung Ja Park ～http://orcid.org/0000-0003-2865-0788

Received September 25, 2021

Revision received October 25, 2021

Accepted November 18, 2021 